\title{
ANALISIS TRIPLE BOTTOM LINE WARUNG KOPI DALAM MENGHADAPI COFFEE SHOP DI KAWASAN BROTONEGORO GRESIK
}

\author{
Atikotul Fauziyah', Anita Handayani2 \\ 1,2Program Studi Manajemen, Fakultas Ekonomi dan Bisnis, \\ Universitas Muhammadiyah Gresik, Gresik, Jawa Timur, Indonesia \\ atikaziy@gmail.com ${ }^{1}$, anita.handayani@umg.ac.id ${ }^{2}$
}

\begin{abstract}
Background - Changes in the lifestyle of young people who mostly prefer to hang out at coffee shops, so that the interest in coffee shops decreases. but contrary to the condition of the coffee shop in the Brotonegoro Gresik area which still survives to obtain optimal profit.

Objective - This study aims to analyze the triple bottom line of coffee shops in the Brotonegoro Gresik area to deal with modern coffee shops in obtaining optimal profit.

Design/Methodology/Approach - The technique used in this research is purposive sampling with structured interviews and unstructured interviews (free)

Findings - The results of this study found that coffee shops pay attention to the environment (planet) by paying attention to the cleanliness of the coffee shop premises, the facilities provided, and paying attention to the layout (layout) of food and beverages being sold. Coffee shops pay attention to service (people), namely by maintaining ethics, paying attention to appearance, and maintaining quality. Profit (profit) as the fulfillment of the necessities of life and business continuity for coffee shop owners in the Brotonegoro Gresik area.

Research implications - The results of this research can be used as a reference for coffee shop owners to provide added value and develop their business.

Research limitations - Research conducted by researchers still has limitations, namely researchers have not explored service quality more deeply, so that the information obtained by researchers in the form of service quality is only based on the dimensions of reliability, certainty and empathy.
\end{abstract}

Keywords: : Environment, Profit, Service, Triple bottom line

\begin{abstract}
Abstrak
Latar Belakang - Perubahan gaya hidup anak muda yang amyoritas lebih memilih nongkrong di coffee shop, sehingga minat warung kopi menurun. namun bertolak belakang dengan kondisi warung kopi di kawasan Brotonegoro Gresik yang masih bertahan untuk memperoleh laba optimal.

Tujuan - Penelitian ini bertujuan untuk mengetahui tentang analisis triple bottom line pada warung kopi di kawasan Brotonegoro Gresik untuk menghadapi coffee shop dalam memperoleh laba yang optimal.

Desain / metodologi / pendekatan - Teknik yang digunakan dalam penelitian ini adalah snowball sampling dengan wawancara terstruktur dan wawancara tidak terstruktur (bebas).

Temuan - Hasil penelitian ini menemukan warung kopi dalam memperhatikan lingkungan (planet) dengan memperhatikan kebersihan tempat warung kopi, fasilitas yang diberikan, dan memperhatikan tata letak (layout) makanan dan minuman yang dijual. Warung kopi dalam
\end{abstract}

http://dx.doi.org/10.30587/mahasiswamanajemen.v2i01.2519

Program Studi Manajemen Universitas Muhammadiyah Gresik Jawa Timur Indonesia 
memperhatikan pelayanan (people) yaitu dengan menjaga etika, memperhatiakan penampilan, dan menjaga kualitas. Laba (profit) sebagai pemenuhan kebutuhan hidup dan keberlangsungan usaha bagi pemilik warung kopi di kawasan Brotonegoro Gresik

Implikasi penelitian - Hasil penelitian ini dapat dijadikan referensi bagi pemilik warung kopi untuk memberikan nilai tambah dan mengembangkan usahanya.

Batasan penelitian - Penelitian yang dilakukan peneliti masih memiliki keterbatasan yaitu peneliti belum menggali kualitas pelayanan lebih mendalam, sehingga informasi yang didapatkan peneliti berupa kualitas layanan hanya berdasarkan dimensi keandalan, kepastian dan empati.

Kata kunci : Lingkungan, Laba, Pelayanan, Triple bottom line

\section{PENDAHULUAN}

Pada era modern saat ini, perkembangan teknologi telah banyak mempengaruhi pola pikir, tingkah dan budaya dalam masyarakat. Perkembangan dunia bisnis yang semakin pesat juga tidak lepas dari peran teknologi. Kebiasaan ngopi atau meminum kopi telah dipengaruhi oleh budaya luar. Minum kopi awalnya hanya dilakukan di warung warung kecil pinggir jalan atau yang biasa disebut warung kopi, namun pada perkembangan bisnis di era modern saat ini menampilkan sebuah usaha baru yang bernama coffee shop yaitu kedai kopi dengan tampilan modern yang dinilai paling sesuai dengan trend dan gaya hidup saat ini. Suasana coffee shop yang nyaman, pilihan menu yang beraneka ragam serta fasilitas yang menarik semakin menambah daya tarik masyarakat untuk mengunjunginya.

Pada saat ini, warung kopi telah menjamur di seluruh wilayah, salah satunya di kawasan Brotonegoro Gresik, yaitu sebuah jalan yang terletak di Desa Suci, Kecamatan Manyar, Kabupaten Gresik. Pada era modern saat ini, banyak bermunculan coffee shop di kawasan Brotonegoro Gresik. Coffee shop di kawasan Brotonegoro Gresik saat ini berjumlah 6 bangunan, sedangkan untuk warung kopi yang sudah berdiri berjumlah 16 bangunan. Banyaknya coffee shop dikhawatirkan berdampak terhadap laba warung kopi, karena semakin ketatnya persaingan bisnis di bidang penjualan kopi.

Suatu usaha akan merasa kesulitan dalam menjalankan bisnisnya apabila masih menggunakan paradigma lama, yaitu mencari keuntungan yang sebanyak-banyaknya tanpa memperdulikan kondisi masyarakat dan lingkungan sekitarnya. Menurut Saleh dan Sukaris (2018) Usaha yang dapat bertahan lama dan berkelanjutan adalah usaha yang dapat memperhatikan kebutuhan masyarakat dan lingkungan sekitar. Suatu usaha yang baik bukan hanya mengejar keuntungan saja, tetapi usaha tersebut perlu 
memperhatikan lingkungan dan peduli terhadap masyarakat seperti konsep dari triple bottom line.

Triple bottom line (TBL) merupakan suatu pandangan bahwa sebuah usaha untuk mempertahankan keberlangsungan hidupnya, usaha tersebut harus memperhatikan “3P" yaitu keuntungan (profit), masyarakat (people) dan lingkungan (planet). Laba (profit) merupakan salah satu faktor yang berperan penting dalam usaha untuk mempertahankan dan meningkatkan usaha yang sedang dijalankan. Pemilik warung kopi memperoleh laba kotor yang digunakan untuk memenuhi kebutuhan sehari-hari pemilik dan untuk keberlanjutan usaha warung kopi agar semakin berkembang. Profit yang diperoleh coffee shop sudah berbentuk laba bersih yaitu laba yang diperoleh setelah laba usaha dikurangi dengan pajak. Laba tersebut digunakan untuk memenuhi kebutuhan pemilik coffee shop, untuk mengembangkan fasilitas-fasilitas coffee shop.

Pelayanan yang diberikan warung kopi menjadi faktor pertimbangan pembeli (people). Pemilik warung kopi melayani pembeli secara langsung hal tersebut berakibat terjalinnya hubungan yang baik oleh penjual dan pembeli. Akan tetapi saat penjual merasa capek, sering kali pelayanan yang diberikan tidak menyenangkan, seperti tidak tersenyum dan cemberut kepada pembeli. Dari sisi penampilan, jika penjual warung kopi seorang laki-laki biasanya menggunakan baju seadaanya yaitu dengan menggunakan kaos dan ada juga yang memakai sarung, ketika pelayannya seorang wanita sering kali menggunakan daster dan tidak berpenampilan menarik. Hal tersebut memberikan ketidak nyamanan bagi pembelinya.

Pelayanan berbeda yang diberikan coffee shop kepada pembeli yaitu sapaan ketika masuk kedalam ruangan, pembeli dihampiri pelayan untuk menanyakan menu apa yang dipesan dan pelayan selalu siap membantu pembeli ketika ada yang dibutuhkan. Pelayan coffee shop melalu peroses training agar memiliki kemampuan yang baik dalam melayani pembeli. Dari sisi penampilan, pelayan coffee shop berpenampilan menarik dengan menggunakan seragam khusus. Pelayanan yang seperti itu menjadikan pembeli merasa lebih dihargai dan timbulnya kepuasan.

Warung kopi dalam memperhatikan lingkungan (planet) dengan memperhatikan penyajian makanan dan minuman yang dijual. Penataan setiap makanan ringan seperti gorengan-gorengan disajikan agar memudahkan pembeli ketika membeli gorengan tersebut, aneka kerupuk atau camilan digantung dengan rapi. Penataan minuman yang dijual juga diperhatikan seperti minuman-minuman dalam botol disusun dengan rapi, 
minuman dalam kemasan juga digantung sesuai jenisnya, antara minuman beraneka ragam rasa dan minuman kopi dalam kemasan, hal tersebut memudahkan pembeli ketika memesan minuman. Warung kopi juga menyediakan tempat yang memadai seperti tempat duduk dan meja untuk menikmati kopi dengan tatanan yang sederhana dan dapat menjadi tempat untuk bersantai orang-orang yang sedang menghilangkan penat. Kebersihan warung kopi hanya seadanya, setiap meja selalu disediakan tempat untuk membuang sisa-sisa rokok agar tidak dibuang sembarangan.

Pada coffee shop dilengkapi dengan fasilitas WIFI yang lancar, meja dan kursi yang nyaman, dan menyediakan toilet serta tempat beribadah membuat pembeli sehingga membuat pelanggan semakin nyaman berlama-lama di coffee shop. Udara disekitar coffee shop tidak pengap karena adanya AC diruangan, dan disediakannya tempat khusus untuk merokok sehingga asap rokok tidak menganggu semua pengunjung. Makanan dan minuman yang disajikan coffee shop sangat beragam. Untuk minuman kopi dibuat dengan memakai alat dan mesin kopi yang modern sehingga memberikan cita rasa tersendiri bagi penikmatnya. Penyajian makanan juga sangat diperhatikan coffee shop sehingga semakin membedakan kualitas antara warung kopi dan coffee shop.

\section{TINJAUAN PUSTAKA}

\section{Triple Bottom Line (3P)}

Felisia (2014) menjelaskan bahwa Triple Bottom Line sebagai tiga pilar yang digunakan dalam pengukuran kinerja, yaitu dari sisi ekonomi, sosial, dan lingkungan. John Elkington mempopulerkan Triple Bottom Line didalam buku Cannibals with Forks, the Triple Bottom Line of Twentieth menyatakan bahwa dalam menjalankan sebuah usaha harus memperhatikan 3P, yaitu profit, people, dan planet. Selain mencari profit, suatu usaha wajib terlibat dalam kesejahteraan masyarakat sekitar (People), serta ikut berkontribusi dalam menjaga kelestarian lingkungan (Planet) (Effendi, 2016).

\section{Warung Kopi}

Warung kopi adalah suatu tempat yang berbentuk kedai atau warung dimana minuman kopi sebagai menu utama yang dijual. Di daerah-daerah warung kopi adalah usaha kecil yang dilakukan oleh sebuah keluarga. Menurut Kurniawan dan Ridlo (2017), Warung kopi adalah sebuah tempat yang tidak terlalu luas tetapi menyediakan banyak hal

http://dx.doi.org/10.30587/mahasiswamanajemen.v2i01.2519 
seperti kopi yang menjadi produk utamanya, berbagai jenis minuman es seperti es teh dan menyediakan makanan ringan sebagai pendamping untuk menikmati kopi. Umumnya warung kopi juga Wi-Fi (Wireless Fidelity).

\section{Coffee Shop}

Di Indonesia menurut Herlyana (2012), kafe berasal dari penyerdanaan kata café. Pengertian harafiahnya terhadap (minuman) kopi, yang akhirnya dikenal sebagai tempat menikmati berbagai macam kopi dan jenis minuman lain seperti soft drink dan sajian makanan ringan lainnya. Menurut Marsum (1993), coffee shop adalah sebuah tempat atau ruangan yang dikelola dengan manajemen terstruktur yang memberikan pelayanan dengan baik kepada pelanggannya berupa hidangan berbagai macam kopi dan lainnya serta fasilitas yang menunjang tempat tersebut.

\section{Laba}

Menurut Subramanyam dan wild (2013) laba adalah ringkasan hasil bersih dari aktivitas operasi usaha dalam periode tertentu yang telah dinyatakan dalam istilah keuangan. Menurut Kasmir (2011), laba kotor (gross profit) artinya laba yang diperoleh sebelum dikurangi biaya-biaya yang menjadi beban perusahaan. Artinya laba keseluruhan yang pertama sekali perusahaan peroleh. Artinya di dalam laba kotor terdapat keuntungan sekaligus terdapat biaya untuk membuat produk atau produksi maupun biaya untuk penyediaan jasa. Sedangkan laba bersih (net profit) merupakan laba yang telah dikurangi biaya-biaya yang merupakan beban perusahaan dalam suatu periode tertentu termasuk pajak.

\section{METODOLOGI PENELITIAN}

\section{Pendekatan Penelitian}

Pendekatan penelitian yang digunakan adalah kualitatif yang bertujuan untuk menjelaskan dan menguraikan secara sistematis terkait permasalahan yang akan diteliti yang selanjutnya ditarik kesimpulan. 


\section{Lokasi dan Fokus Penelitian}

Tempat penelitian ini dilakukan di warung kopi kawasan Brotonegoro di Desa Suci, Kecamatan Manyar, Kabupaten Gresik. Penelitian ini difokuskan pada cara memperoleh laba yang optimal melalui konsep triple bottom line menghadapi coffee shop.

\section{Sumber Data dan Jenis Data}

Sumber data yang digunakan peneliti adalah data primer yaitu data yang diperoleh secara langsung dari informan melalui wawancara. Melakukan wawancara dengan para pemilik warung kopi di kawasan Brotonegoro Gresik.

\section{Teknik Pengumpulan Data}

Teknik pengumpulan data yang digunakan dalam penelitian ini adalah teknik snowball sampling, yaitu teknik pengambilan sampel dengan bantuan key-informan, dan dari keyinforman inilah akan berkembang sesuai petunjuknya.

\section{Unit Analisis}

Menurut Sugiyono (2016), unit analisis adalah sesuatu yang berkaitan dengan fokus/komponen yang diteliti. Penelitian ini dilakukan untuk mengamati secara mendalam aktivitas orang-orang pada tempat tertentu. Pelaku atau orang dalam penelitian ini adalah para pemilik warung kopi. Aktivitas sehari-hari pemilik warung kopi yaitu berdagang untuk mendapatkan laba. Hubungan antara pemilik warung kopi dengan kegiatan yang selalu dilakukan dan tempat selalu menghasilkan situasi sosial tertentu.

\section{Informan}

Informan (subyek) dalam penelitian ini terdiri dari 5 orang. Peneliti melakukan observasi dan wawancara dengan pemilik warung kopi di kawasan Brotonegoro Gresik. Informan peneliti telah ditetapkan sebelumnya oleh peneliti dengan teknik Snowball Sampling.

\section{Teknik Analisis Data}

Teknik analisis data pada penelitian ini adalah analisis data kualitatif yang berupa kumpulan berwujud kata-kata dan bukan rangkaian angka serta tidak dapat disusun dalam kategori-kategori/struktur klasifikasi. 


\section{Uji Keabsahan Data}

Keabsahan data yang digunakan adalah member check. Member check menurut Sugiyono (2013) adalah proses pengecekan data yang diperoleh peneliti kepada pemberi data. Tujuan member check adalah untuk mengetahui seberapa jauh data yang diperoleh sesuai dengan apa yang diberikan oleh pemberi data.

\section{HASIL DAN PEMBAHASAN}

\section{Hasil}

Berdasarkan wawancara dan observasi yang telah dilakukan, jumlah masyarakat di kawasan Brotonegoro Suci yang memiliki usaha warung kopi sebanyak 16 orang. Tujuan pemilik warung kopi berdagang adalah sebagai mata pencaharian untuk memenuhi kebutuhan sehari-hari dan menjalankan usaha warung kopi tersebut bersama-sama keluarganya. Beberapa dari pemilik warung kopi membuka usaha tersebut sebagai sampingan untuk mengisi waktu luang, karena disamping membuka usaha warung kopi pemilik sudah memiliki pekerjaan tetap.

Informan pertama atau selaku key informan yaitu Bapak Juan pengurus Warung Kopi Jurang, informan kedua yaitu Bapak Adi selaku pemilik Warung Kopi Remen, informan ketiga yaitu Bapak Arka selaku pemilik Warung Kopi Salman, informan keempat yaitu Bapak Antok selaku pemilik Warung Kopi Pingpong, informan kelima yaitu Bapak Aswin selaku pengurus Warung Kopi Boulder. Analisis warung kopi untuk memperoleh laba yang optimal dalam memperhatikan lingkungan (planet) adalah memperhatikan kebersihan, fasilitas, layout meja dan kursi dan tata letak makanan dan minuman yang dijual. Warung kopi untuk memperoleh laba yang optimal yaitu memperhatikan lingkungan dengan analisis diatas. Lingkungan warung kopi yang baik dan membuat nyaman pembeli dan akan semakin banyak menarik pembeli baru sehingga laba yang didapatkan warung kopi meningkat.

Analisis warung kopi untuk memperoleh laba yang optimal dalam memperhatikan pelayanan terhadap pembeli (people) adalah menjaga etika, memperhatiakan penampilan, dan menjaga kualitas makanan dan minuman yang dijualnya. Dalam memperhatikan pelayanan pemilik warung kopi perlu memperhatikan analisis diatas untuk memperoleh laba yang optimal. Pelayanan baik yang diberikan kepada pembeli akan membuat nyaman dan betah ngopi di warung kopi, sehingga laba yang didapatkan warung kopi meningkat. Laba (profit) yang 
didapatkan digunakan sebagai kebutuhan hidup pemilik warung kopi dan sebagai keberlangsungan usaha untuk kedepannya.

\section{Pembahasan}

Hasil penelitian kualitatif ini menyatakan bahwa analisis triple bottom line warung kopi dalam menghadapi coffee shop dalam memperoleh laba yang optimal yaitu memperhatikan lingkungan (planet) dengan memperhatikan kebersihan, fasilitas, layout. Dalam memperhatikan pelayanan terhadap pembeli (people) adalah menjaga etika, memperhatiakan penampilan, dan menjaga kualitas makanan dan minuman yang dijualnya. Dan laba (profit) merupakan kebutuhan hidup dan keberlangsungan usaha. Menurut Parasuraman, Zethmal dan Berry dalam Teas (1993) mendefinisikan persepsi sebagai kepercayaan pelanggan yang berhubungan dengan jasa yang diterima. Hal ini berarti citra kualitas jasa yang baik bukanlah berdasarkan sudut pandang atau persepsi pihak penyedia jasa, melainkan berdasarkan dari pandangan pelanggan. Pelangganlah yang mengkonsumsikan atau menikmati jasa perusahaan, sehinggga merekalah yang seharusnya menentukan kualitas jasa.

Faktor utama penentu kualitas layanan jasa sebagai berikut: 1. Reliability (Keandalan). Yaitu kemampuan untuk mewujudkan pelayanan yang dijanjikan dengan handal dan akurat. 2. Responsiveness (Daya tanggap). Yaitu kemauan untuk membantu para konsumen dengan menyediakan pelayanan yang cepat dan tepat. 3. Assurance (Jaminan). Yaitu meliputi pengetahuan, kemampuan, dan kesopanan atau kebaikan dari personal serta kemampuan untuk mendapatkan kepercayaan dan keinginan. 4. Empathy (Empati). Yaitu mencakup menjaga dan memberikan tingkat perhatian secara individu atau pribadi terhadap kebutuhan-kebutuhan konsumen. 5. Tangible (Bukti langsung). Yaitu meliputi fasilitas fisik, peralatan atau perlengkapan, harga, dan penampilan personal dan material tertulis.

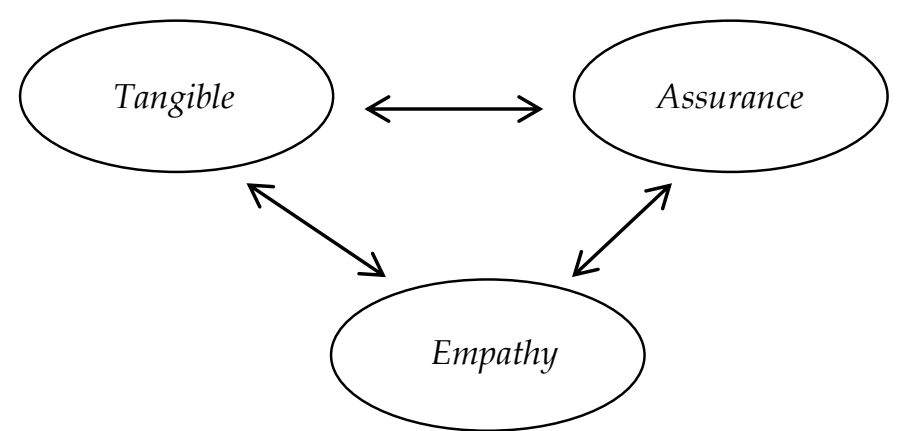

Sumber : Diolah Peneliti, 2021

http://dx.doi.org/10.30587/mahasiswamanajemen.v2i01.2519 


\section{Gambar 1}

Interprestasi Hasil Tentang Analisis Triple Bottom Line Warung Kopi Dalam Menghadapi Coffee Shop Di Kawasan Brotonegoro Gresik



Sumber : Diolah Peneliti, 2021

Gambar 2

Interprestasi Hasil Tentang Kualitas Pelayanan Menurut Parasuraman, dkk (1993)

\section{KESIMPULAN}

Berdasarkan hasil penelitian dapat ditarik kesimpulan sebagai berikut :

1. Warung kopi dalam memperhatikan lingkungan (planet) untuk memperoleh laba yang optimal adalah memperhatikan kebersihan, fasilitas, layout. Yaitu dengan memperhatikan kebersihan warung kopi, menyediakan fasilitas seperti WIFI, tempat kamar mandi dan tempat untuk solat, memperhatikan layout kursi dan meja untuk pembeli dan tata letak makanan dan minuman yang dijualnya.

2. Warung kopi dalam memperhatikan pelayanan (people) untuk memperoleh laba yang optimal dengan menjaga etika berprilaku sopan dan sabar kepada pembeli, memperhatiakan penampilan, dan menjaga kualitas kopi dari biji kopi premium dan menjual makanan yang berkualitas.

3. Laba (profit) bagi pemilik warung kopi merupakan pemenuhan kebutuhan hidup dan keberlangsungan usaha.

\section{REKOMENDASI}

Bagi peneliti selanjutnya bisa memperdalam informasi tentang pelayanan yang diberikan warung kopi. Pelayanan yang perlu diperdalam yaitu dimensi kualitas produk seperti cita rasa makanan dan minuman yang dijual, makanan dan minum dari bahan-bahan yang berkualitas, penyajian makanan dan minuman sangat higenis.

http://dx.doi.org/10.30587/mahasiswamanajemen.v2i01.2519 


\section{DAFTAR PUSTAKA}

Effendi, M. A. (2016). The Power of Good Corporate Governance. Edisi 2. Jakarta: Salemba Empat.

Felisia, A. L. (2014). Triple Bottom Line dan Sustainability. Bina Ekonomi Majalah Ilmiah Fakultas Ekonomi Unpar, Vol. 18, No.1. hal. 14-27.

Herlyana, E. (2012). Fenomena Coffe Shop sebagai Gejala Gaya Hidup Baru. Thaqafiyyat Vol. 13, No. 1, 187-204.

Kasmir. (2011). Analisis Laporan Keuangan, Edisi 1, Cetakan 4. Jakarta: PT Raja Grafindo Persada.

Kurniawan, A., \& Ridlo, M. R. (2017). Pelaku Konsumtif Remaja Penikmat Warung Kopi. Vol. 32, No. 1.

Marsum, W. (1993). Restoran dan Segala Permasalahannya. Yogyakarta: Andi Offset Publishing.

Parasuraman, A, Valarie A. Zeithaml and Leonard L. Berry. (1993). SERVQUAL: A Multi-item Scale for Measuring Consumer Perceptions of Service Quality, dalam Journal of Retailing. Vol. 64. No. 1

Saleh, M., \& Sukaris. (2018). Corporate Social Responsibility Best Practice PT PJB UP Gresik. UMG Press. Gresik.

Subramanyam, K. R., \& Wild, J. J. (2013). Analisis Laporan Keuangan. Edisi 10. Buku Satu. Yang Dialihbahasakan oleh Dewi Yanti. Jakarta: Salemba Empat. 